\title{
Dialelo entre linhagens de uma população de pepino do tipo 'Caipira'
}

\author{
Antonio Ismael Inácio Cardoso \\ UNESP, C. Postal 237, 18603-970 Botucatu-SP; E-mail: ismaeldh@fca.unesp.br
}

\section{RESUMO}

Este trabalho foi realizado para avaliar as capacidades geral e específica de combinação de seis linhagens de pepino 'Caipira', hibridizadas em um esquema dialélico, totalizando 15 híbridos experimentais (H-1 a H-15) possíveis (sem recíprocos). O delineamento foi em blocos ao acaso, com 23 tratamentos (6 linhagens, 15 híbridos experimentais e dois híbridos comerciais: 'Guarani' e 'Safira'), quatro repetições e 5 plantas por parcela. Foram avaliadas as seguintes características: número e massa total de frutos por planta, número e massa de frutos comerciais por planta e taxa de frutos comerciais. O híbrido ' $\mathrm{H}-5$ ' foi o que apresentou as maiores heteroses para produção de frutos (45 a 51\%), com produção comercial (em número de frutos por planta) superior a cinco linhagens e ao híbrido comercial 'Safira'. Tanto os efeitos aditivos como os não aditivos foram significativos para as características de produção de frutos (número e massa por planta), resultando em elevadas capacidades específicas de combinação para a maioria das combinações entre as linhagens. Das 75 estimativas de heterose obtidas, apenas três foram negativas.

\begin{abstract}
Diallel among lines of a 'Caipira' type cucumber population

The objective of this work was to evaluate general and specific combining ability of six 'Caipira' cucumber lines, hybridized in a diallel cross, totalizing 15 experimental hybrids ( $\mathrm{H}-1$ to $\mathrm{H}-15)$, without reciprocals. The experimental design was randomized blocks with 23 treatments (6 lines, 15 experimental hybrids and two commercial hybrids: 'Safira' and 'Guarani'), four replicates and 5 plants per plot. The following characteristics were evaluated: total fruit number and weight per plant, commercial fruit number and weight per plant and rate of commercial fruits. Hybrid H-5 showed the highest heterosis for fruit yield ( 45 to $51 \%$ ), and had commercial yield (fruit number per plant) superior to five lines and to 'Safira' hybrid. Additive and non additive effects were significant for fruit yield (number and weight) per plant, resulting in high specific combining ability for most of lines combinations. From the 75 heterosis estimates, only three were negative.
\end{abstract}

Keywords: Cucumis sativus, yield, breeding.

Palavras-chave: Cucumis sativus, produção, melhoramento.

(Recebido para publicação em 15 de agosto de 2005; aceito em 29 de maio de 2006)

A cultura do pepino (Cucumis sativus L.) não se adapta ao cultivo sob baixas temperaturas, sendo o desenvolvimento da planta favorecido por temperaturas superiores a $20^{\circ} \mathrm{C}$ (Lower \& Edwards, 1986; Robinson \& DeckerWalters, 1999). Este foi um dos motivos pelos quais os produtores passaram a cultivar pepino em ambiente protegido a partir da década de 80 (Cañizares, 1998). Sob condições de cultivo protegido, os produtores buscam obter o máximo de produtividade e, para isto, buscam as cultivares mais adaptadas e produtivas, geralmente híbridos $\mathrm{F}_{1}$. A utilização de híbridos se tornou comum em pepino devido à maior produtividade $\mathrm{e}$ à maior uniformidade e qualidade dos frutos (Viggiano, 1994; Maluf, 2001).

A superioridade de híbridos de pepino foi constatada há mais de oito décadas, em 1916, por Hayes \& Jones (citados por Ghaderi \& Lower, 1978), onde foi verificada presença de heterose para produção de frutos e número de frutos por planta. Ghaderi \& Lower (1978) observaram heterose principalmente em características vegetativas. Já Delaney
\& Lower (1987) observaram heterose significativa para produção, número de ramificações e comprimento de entrenó. Filgueira et al. (1986) relataram heterose positiva tanto para produção total como para produção precoce em linhagens e híbridos $\mathrm{F}_{1}$ experimentais de pepino 'Caipira' em cultura rasteira. Heterose positiva também foi relatada em um dialelo entre quatro linhagens de pepino por Li et al. (1995) para produção total, produção precoce, número de frutos, peso médio de frutos e área foliar, e heterose negativa para comprimento de haste. Já Cui et al. (1992) reportaram maior precocidade nos híbridos em um dialelo parcial $4 \times 4$ quando comparados aos respectivos parentais.

Apesar da heterose ser conhecida para pepino, Cramer \& Wehner (1999) relataram que há possibilidade de serem obtidas linhagens tão boas quanto híbridos, com uma baixa depressão por endogamia. Segundo Robinson (1999), têm sido desenvolvidas linhagens em pepino sem perda de vigor, sendo que a depressão por endogamia não é um fator limitante para produção de semen- tes híbridas em cucurbitáceas. Segundo Fehr (1987), o desenvolvimento de linhagens endogâmicas e a obtenção de híbridos comerciais, a partir de populações segregantes, apresentam cinco fases: formação de uma população segregante; endogamia de indivíduos da população até o nível adequado de homozigose; avaliação da performance das linhagens; avaliação da capacidade geral de combinação das linhagens; avaliação das linhagens em híbridos comerciais potenciais.

Deste modo, os primeiros passos no programa de melhoramento são obtenção de uma população segregante, promover a endogamia e avaliação das linhagens. Depois deve-se avaliar a capacidade de cruzamento destas linhagens, geralmente em cruzamentos dialélicos. A análise de cruzamentos dialélicos é um método comumente utilizado na investigação de caracteres quantitativos no melhoramento vegetal. Sua utilização tem origem a partir do desenvolvimento dos conceitos da capacidade geral e específica de combinação, estabelecidos por Sprague \& 
Tabela 1. Número de frutos total e comercial por planta, massa de frutos total e comercial por planta e taxa de frutos comerciais nos diferentes tratamentos. São Manuel (SP), UNESP, 2004.

\begin{tabular}{|c|c|c|c|c|c|}
\hline Tratamento & $\begin{array}{c}\text { Total frutos } \\
\left(\mathbf{n}^{\circ}\right)\end{array}$ & $\begin{array}{c}\text { Massa } \\
\text { frutos } \\
\text { (g/planta) }\end{array}$ & $\begin{array}{c}\text { Frutos } \\
\text { comerciais } \\
\left(n^{\circ}\right)\end{array}$ & $\begin{array}{c}\text { Massa } \\
\text { frutos } \\
\text { comerciais } \\
\text { (g/planta) }\end{array}$ & $\begin{array}{c}\text { Taxa frutos } \\
\text { comerciais } \\
(\%)\end{array}$ \\
\hline Safira & $19,8 a b c^{1}$ & $3618 a b c$ & $16,6 \mathrm{~b}$ & $3157 \mathrm{ab}$ & $83 a b$ \\
\hline Guarani & $22,4 a b$ & $3942 a b$ & $19,6 a b$ & $3532 a b$ & $87 a b$ \\
\hline L-1 & $19,1 \mathrm{bc}$ & $3090 \mathrm{bc}$ & $17,2 \mathrm{~b}$ & 2862 bc & $91 \mathrm{ab}$ \\
\hline L-2 & $14,1 \mathrm{c}$ & $2319 \mathrm{c}$ & $8,5 \mathrm{c}$ & $1551 \mathrm{c}$ & $60 \mathrm{c}$ \\
\hline L-3 & $19,8 \mathrm{abc}$ & $3434 a b c$ & $15,2 \mathrm{bc}$ & 2822 bc & $77 \mathrm{~b}$ \\
\hline$L-4$ & $19,5 \mathrm{abc}$ & $3243 a b c$ & $15,6 \mathrm{bc}$ & 2731 bc & $79 a b$ \\
\hline L-5 & $22,1 a b$ & $3778 a b c$ & $19,1 a b$ & $3387 a b$ & $85 a b$ \\
\hline L-6 & $18,4 \mathrm{bc}$ & $3413 a b c$ & $16,5 \mathrm{bc}$ & $2149 a b$ & $90, a b$ \\
\hline $\mathrm{H}-1$ (L-1 x L-2) & $19,8 \mathrm{abc}$ & $3582 a b c$ & $17,8 a b$ & $3320 a b$ & $90 a b$ \\
\hline $\mathrm{H}-2$ (L-1 x L-3) & $21,2 a b c$ & $3802 \mathrm{abc}$ & $18,6 a b$ & $3427 a b$ & $88 a b$ \\
\hline $\mathrm{H}-3$ (L-1 x L-4) & $22,3 a b$ & $3669 a b c$ & $20,1 a b$ & $3371 a b$ & $90 a b$ \\
\hline$H-4(L-1 \times L-5)$ & $22,2 a b$ & $3874 a b$ & $20,2 a b$ & $3567 a b$ & $91 \mathrm{ab}$ \\
\hline$H-5(L-1 \times L-6)$ & $27,1 \mathrm{a}$ & $4711 \mathrm{a}$ & $25,5 \mathrm{a}$ & 4524 a & $94 \mathrm{a}$ \\
\hline $\mathrm{H}-6(\mathrm{~L}-2 \times \mathrm{L}-3)$ & $18,8 \mathrm{bc}$ & $3630 a b c$ & $16,2 \mathrm{bc}$ & $3209 a b$ & $86 a b$ \\
\hline $\mathrm{H}-7$ (L-2 x L-4) & $20,8 a b c$ & $3633 a b c$ & $17,3 \mathrm{~b}$ & $3058 \mathrm{abc}$ & $83 a b$ \\
\hline $\mathrm{H}-8(\mathrm{~L}-2 \times \mathrm{L}-6)$ & $20,3 a b c$ & $4072 a b$ & $17,8 a b$ & $3681 a b$ & $88 a b$ \\
\hline$H-9(L-3 \times L-4)$ & $20,9 a b c$ & $3517 \mathrm{abc}$ & $17,4 a b$ & $3037 \mathrm{abc}$ & $83 a b$ \\
\hline $\mathrm{H}-10$ (L-3 x L-5) & $19,6 \mathrm{abc}$ & $3760 \mathrm{abc}$ & $17,3 \mathrm{~b}$ & $3420 \mathrm{ab}$ & $89 a b$ \\
\hline $\mathrm{H}-11(\mathrm{~L}-3 \times \mathrm{L}-6)$ & $20,1 \mathrm{abc}$ & $3704 a b c$ & $16,3 \mathrm{bc}$ & $3192 a b$ & $81 a b$ \\
\hline $\mathrm{H}-12(\mathrm{~L}-4 \times \mathrm{L}-5)$ & $22,3 a b$ & $3709 \mathrm{abc}$ & $19,4 a b$ & $3344 a b$ & $87 a b$ \\
\hline $\mathrm{H}-13(\mathrm{~L}-4 \times \mathrm{L}-6)$ & $20,0 a b c$ & $3478 a b c$ & $17,5 a b$ & $3080 a b c$ & $88 a b$ \\
\hline $\mathrm{H}-14(\mathrm{~L}-5 \times \mathrm{L}-6)$ & $22,5 a b$ & $4031 a b$ & $18,8 a b$ & $3520 a b$ & $84 a b$ \\
\hline $\mathrm{H}-15(\mathrm{~L}-2 \times \mathrm{L}-5)$ & $24,7 a b$ & $4374 a b$ & $20,0 a b$ & $3732 a b$ & $81 a b$ \\
\hline C.V. (\%) & 14,3 & 15,8 & 17,1 & 17,9 & 6,5 \\
\hline
\end{tabular}

${ }^{1}$ Médias seguidas pela mesma letra, nas colunas, não diferem pelo teste de Tukey (5\%).

Tatum (1942). A capacidade geral de combinação (CGC) é uma medida do comportamento relativo de uma linhagem em uma série de cruzamentos e está associada a efeitos genéticos aditivos. A capacidade específica de combinação (CEC) representa o desvio, para melhoria ou não, de um determinado cruzamento, tomando por base a média da CGC dos parentais. É resultado dos efeitos de dominância, epistasia e vários tipos de interações.

No Brasil, a maioria dos híbridos de pepino do tipo japonês são partenocárpicos, por isso podem ser cultivados em ambiente protegido durante o ano todo (Filgueira, 2000; Cardoso \& Silva, 2003). As cultivares e híbridos de pepino 'Caipira' não apresentam partenocarpia (Cardoso, 2002), o que dificulta o seu plantio em estufas fechadas, devido a redução na possibilidade de entrada de insetos polinizadores. Entretanto, muitos produtores tem plan-
$7 \mathrm{~m}$ de largura por $20 \mathrm{~m}$ de comprimento e pé direito de $2,0 \mathrm{~m}$, com cobertura de polietileno transparente de $75 \mu \mathrm{m}$ de espessura. As laterais permaneceram abertas, possibilitando a entrada de insetos polinizadores.

Foram estudadas seis linhagens obtidas de uma população de pepino 'Caipira' originada do cruzamento entre os híbridos 'Safira' (tipo 'Caipira', da Sakata) e 'Hatem' (tipo 'Beit Alpha' ou holandês, da SVS). O híbrido resultante foi retrocruzado com o 'Safira' obtendo-se a população ('Safira' $x$ 'Hatem') x 'Safira' $F_{1} R C_{1}$. Plantas desta população foram intercruzadas para obtenção da população $\mathrm{F}_{2} \mathrm{RC}_{1}$ que foi a população de onde foram extraídas seis linhagens com autofecundações sucessivas pelo método do "single seed descent - SSD" (Brim, 1966). Foram obtidos quinze híbridos experimentais possíveis (sem recíprocos) no cruzamento dialélico entre as seis linhagens.

A semeadura (03/08/04) foi feita em bandejas de poliestireno expandido de 128 células, com transplante em 26/08/ 04 , no espaçamento de $1,0 \mathrm{~m}$ entre linhas e $0,45 \mathrm{~m}$ entre plantas. A adubação de base constou da aplicação de composto $\left(5 \mathrm{~L} \mathrm{~m}^{-2}\right)$ e adubo formulado 4-14-8 (150 $\left.\mathrm{g} \mathrm{m}^{-2}\right)$. As adubações em cobertura foram realizadas a cada sete dias colocando-se $2 \mathrm{~g}$ de nitrato de cálcio por planta até o início do florescimento e $2 \mathrm{~g}$ de nitrato de cálcio mais $2 \mathrm{~g}$ de nitrato de potássio por planta após o início do florescimento. Cada planta foi tutorada individualmente e foi feita a eliminação de todas as brotações e flores até o $5^{\circ}$ nó da haste principal, retirada do meristema das ramas laterais (após o $6^{\circ}$ nó da haste principal) entre a segunda e terceira folhas e retirada do meristema apical da planta ao atingir a altura do arame (cerca de 1,80 $\mathrm{m}$ de altura). Foram avaliadas as seguintes características: produção de frutos (número e massa), total e comercial (frutos sem defeitos aparentes e retos) por planta e taxa de frutos comerciais. Os frutos foram colhidos a cada 2 dias, quando atingiam cerca de $15 \mathrm{~cm}$ de comprimento. O período de colheita foi de 04/10/04 a 16/11/04.

Foram avaliados 23 tratamentos: 15 híbridos experimentais (H-1 a H-15), 
seis linhagens parentais (L-1 a L-6) e dois híbridos comerciais ('Guarani' e 'Safira'), em um delineamento em blocos ao acaso, com 4 repetições de 5 plantas. Foram realizadas as análises de variância para cada característica e as médias dos 23 tratamentos foram comparadas pelo teste de Tukey (5\%). Para estimar as capacidades geral e específica das linhagens e híbridos foi utilizado o método 2, modelo fixo, definido por Griffing (1956). As análises foram realizadas com o programa Genes (Cruz, 2001).

\section{RESULTADOS E DISCUSSÃO}

A linhagem L-2 foi o tratamento com menores produções, tanto total como comercial (Tabela 1), provavelmente por apresentar grande número de flores masculinas e poucas femininas tanto na haste principal como nas ramificações laterais. Em média, as linhagens foram menos produtivas que os híbridos experimentais, com uma indicação de que há heterose, conforme será descrito posteriormente. $\mathrm{O}$ híbrido $\mathrm{H}-5$ foi o mais produtivo, se destacando, principalmente, em relação a produção comercial, tendo sido superior a cinco das seis linhagens e superior ao híbrido comercial 'Safira' no número de frutos comerciais. Com exceção da linhagem L-2, todas as outras linhagens e os híbridos experimentais (exceto H-5) não diferiram dos híbridos comerciais (Tabela 1), demonstrando o potencial dos mesmos. Com relação aos valores de produção total e comercial obtidos, foram semelhantes aos obtidos por Cardoso (2002) e por Godoy et al. (2005) na avaliação dos híbridos 'Safira' e 'Guarani', também nas condições de São Manuel (SP).

Quanto a taxa de frutos comerciais, foram poucas as diferenças significativas. A linhagem L-2 foi inferior a todos os outros tratamentos (Tabela 1) por apresentar grande número de frutos tortos, provavelmente por ser o material com frutos mais compridos e finos. Excetuando-se esta linhagem, a única diferença foi a superioridade do híbrido H-5 em relação a linhagem L-3. A frequiência de frutos defeituosos foi baixa, resultando em elevada taxa de frutos comerciais para a maioria dos tratamentos. Os valores observados foram supe-

Tabela 2. Estimativas dos efeitos da capacidade geral de combinação das linhagens e dos quadrados médios para capacidade geral $\left(\mathrm{QM}_{\mathrm{CGC}}\right)$ e específica $\left(\mathrm{QM}_{\mathrm{CEC}}\right)$ de combinação para as características número de frutos total e comercial por planta, massa de frutos total e comercial por planta e taxa de frutos comerciais. São Manuel (SP), UNESP, 2004.

\begin{tabular}{|c|c|c|c|c|c|}
\hline Linhagem & $\begin{array}{l}\text { Total frutos } \\
\left(n^{\circ}\right)\end{array}$ & $\begin{array}{c}\text { Massa } \\
\text { frutos } \\
\text { (g/planta) }\end{array}$ & $\begin{array}{c}\text { Frutos } \\
\text { comerciais } \\
\left(n^{\circ}\right)\end{array}$ & $\begin{array}{c}\text { Massa } \\
\text { frutos } \\
\text { comercia is } \\
\text { (g/planta) }\end{array}$ & $\begin{array}{c}\text { Taxa frutos } \\
\text { comerciais } \\
(\%)\end{array}$ \\
\hline $\mathrm{L}-1$ & 0,711 & 30,4 & 1,578 & 159,0 & 4,91 \\
\hline $\mathrm{L}-2$ & $-1,580$ & $-218,1$ & $-2,254$ & $-319,9$ & $-5,77$ \\
\hline L-3 & $-0,625$ & $-36,6$ & $-0,988$ & $-91,5$ & $-1,87$ \\
\hline L-4 & 0,020 & $-147,9$ & $-0,154$ & $-163,6$ & $-0,57$ \\
\hline$L-5$ & 1,282 & 216,1 & 1,229 & 211,8 & 0,80 \\
\hline L-6 & 0,193 & 156,1 & 0,589 & 204,2 & 2,51 \\
\hline QMCGC & $32,48^{* *}$ & $913540^{*}$ & $66,71^{* *}$ & $1595743^{* *}$ & $436,6^{* *}$ \\
\hline QMCEC & $24,12^{* *}$ & $895663^{* *}$ & $27,76^{* *}$ & $1051287^{* *}$ & $128,5^{\star \star}$ \\
\hline QMCGC / QMCEC & 1,35 & 1,02 & 2,40 & 1,52 & 3,40 \\
\hline
\end{tabular}

$*, * *=$ significativo a $5 \%$ e a $1 \%$, respectivamente, pelo teste $\mathrm{F}$.

riores aos relatados por Cardoso (2002) - cerca de $64 \%$ - provavelmente porque conseguiu-se manter as plantas sadias e bem nutridas até próximo do final das colheitas, período com maior incidência de frutos defeituosos (Demattê, 1978; Nomura \& Cardoso, 2000).

Tanto a capacidade geral (CGC) como a específica (CEC) de combinação foram altamente significativas para todas as características avaliadas (Tabelas 2 e 3). Segundo Vencovsky \& Barriga (1992), o quociente entre os quadrados médios da CGC e CEC reflete o predomínio de uma ou outra. Para a maioria das características avaliadas não houve um predomínio da CGC ou da CEC, conforme demonstram os quocientes que variaram de 1,02 a 3,40 (Tabela 2), mostrando que para estas características tanto os efeitos aditivos como os não aditivos (dominância e epistasia) são importantes na herança genética. Deste modo, a média das linhagens não pode ser o único fator na escolha das mesmas como parentais de híbridos. Apenas para a taxa de frutos comerciais, com quociente de 3,4 , pode-se dizer que os efeitos aditivos se sobrepõem aos não aditivos, tanto que foi para esta característica que foram obtidas as menores estimativas para heterose (Tabela 4).

A linhagem L-5 foi a que apresentou os maiores valores para CGC para a maioria das características (Tabela 2), ou seja, foi a linhagem com maior concentração de genes com efeitos aditivos fa- voráveis para aumento de produção por planta. O híbrido H-5 apresentou a melhor complementação em loci gênicos com efeitos não aditivos para as características de produção de frutos, com os maiores valores para CEC (Tabela 3).

Deve ser ressaltado que, sendo este um modelo fixo (Griffing, 1956), as estimativas são válidas para o conjunto de parentais testados e, em outras combinações dialélicas, a capacidade de combinação poderá ser diferente, dependendo da constituição genética dos demais parentais (Vencovsky \& Barriga, 1992).

A superioridade do híbrido H-5 se deve a dois fatores: a) combinação de duas linhagens (L-1 e L-6) com elevadas CGC (sempre entre as três mais elevadas) (Tabela 2) para número de frutos por planta (total e comercial), ou seja, maior acúmulo de genes com ação aditiva favoráveis; b) elevadas estimativas para CEC (Tabela 3), com a melhor complementação em loci gênicos com efeitos não aditivos (provavelmente dominância). O que mais chama a atenção são os valores absolutos para CEC tanto para número total como comercial de frutos por planta, de 5,49 e 5,62, respectivamente. Isto significa que apenas pela ação gênica não aditiva (especificidade do cruzamento) há um aumento de mais de cinco frutos por planta ( $25 \%$ da produção deste híbrido). Portanto, este híbrido H-5 apresenta grande quantidade de genes com efeitos aditivos favoráveis (vindos de am- 
Tabela 3. Estimativas dos efeitos da capacidade específica de combinação dos híbridos para as características número de frutos total e comercial por planta, massa de frutos total e comercial por planta e taxa de frutos comerciais. São Manuel (SP), UNESP, 2004.

\begin{tabular}{|c|c|c|c|c|c|}
\hline $\begin{array}{l}\text { Híbrido } \\
\text { (linhagens) }\end{array}$ & $\begin{array}{c}\text { Total frutos } \\
\left(n^{\circ}\right)\end{array}$ & $\begin{array}{c}\text { Massa } \\
\text { frutos } \\
\text { (g/planta) }\end{array}$ & $\begin{array}{c}\text { Frutos } \\
\text { comerciais } \\
\left(n^{\circ}\right)\end{array}$ & $\begin{array}{c}\text { Massa } \\
\text { frutos } \\
\text { comerciais } \\
\text { (g/planta) }\end{array}$ & $\begin{array}{c}\text { Taxa frutos } \\
\text { comerciais } \\
(\%)\end{array}$ \\
\hline $\mathrm{H}-1$ (L-1 x L-2) & $-0,05$ & 116 & 0,72 & 243 & 5,52 \\
\hline$H-2(L-1 \times L-3)$ & 0,33 & 155 & 0,31 & 123 & $-0,21$ \\
\hline$H-3(L-1 \times L-4)$ & 0,87 & 133 & 0,98 & 138 & 0,95 \\
\hline$H-4(L-1 \times L-5)$ & $-0,50$ & -26 & $-0,36$ & -41 & 0,37 \\
\hline$H-5(L-1 \times L-6)$ & 5,49 & 871 & 5,62 & 924 & 1,64 \\
\hline$H-6(L-2 \times L-3)$ & 0,31 & 231 & 1,71 & 383 & 8,56 \\
\hline H-7 (L-2 x L-4) & 1,62 & 246 & 1,99 & 305 & 4,72 \\
\hline$H-8(L-2 \times L-6)$ & 0,90 & 481 & 1,70 & 559 & 6,51 \\
\hline$H-9(L-3 \times L-4)$ & 0,78 & 48 & 0,82 & 55 & 0,73 \\
\hline $\mathrm{H}-10(\mathrm{~L}-3 \times \mathrm{L}-5)$ & $-1,80$ & -73 & $-0,66$ & 62 & 4,76 \\
\hline$H-11(L-3 \times L-6)$ & $-0,18$ & -69 & $-1,07$ & -158 & $-4,46$ \\
\hline$H-12(L-4 \times L-5)$ & 0,21 & -12 & 0,63 & 58 & 1,80 \\
\hline$H-13(L-4 \times L-6)$ & $-0,99$ & -184 & $-0,71$ & -198 & 0,65 \\
\hline$H-14(L-5 \times L-6)$ & 0,25 & 6 & $-0,75$ & -133 & $-4,55$ \\
\hline H-15 (L-2 x L-5) & 4,27 & 723 & 3,34 & 602 & 1,38 \\
\hline
\end{tabular}

Tabela 4. Estimativas das heteroses (\%) dos híbridos para as características número de frutos total e comercial por planta, massa de frutos total e comercial por planta e taxa de frutos comerciais. São Manuel (SP), UNESP, 2004.

\begin{tabular}{|c|c|c|c|c|c|}
\hline Híbrido (linhagens) & $\begin{array}{c}\text { Total frutos } \\
\left(\mathbf{n}^{\circ}\right)\end{array}$ & $\begin{array}{l}\text { Massa } \\
\text { frutos } \\
\text { (g/planta) }\end{array}$ & $\begin{array}{c}\text { Frutos } \\
\text { comerciais } \\
\left(n^{\circ}\right)\end{array}$ & $\begin{array}{c}\text { Massa } \\
\text { frutos } \\
\text { comerciais } \\
\text { (g/planta) }\end{array}$ & $\begin{array}{c}\text { Taxa frutos } \\
\text { comerciais } \\
(\%)\end{array}$ \\
\hline $\mathrm{H}-1$ (L-1 x L-2) & 20 & 32 & 38 & 50 & 19 \\
\hline$H-2(L-1 \times L-3)$ & 9 & 17 & 15 & 21 & 5 \\
\hline$H-3(L-1 \times L-4)$ & 16 & 16 & 23 & 21 & 6 \\
\hline$H-4(L-1 \times L-5)$ & 8 & 13 & 11 & 14 & 4 \\
\hline$H-5$ (L-1 x L-6) & 45 & 45 & 51 & 51 & 4 \\
\hline$H-6(L-2 \times L-3)$ & 11 & 26 & 37 & 47 & 26 \\
\hline $\mathrm{H}-7$ (L-2 x L-4) & 24 & 27 & 44 & 43 & 20 \\
\hline$H-8(L-2 \times L-6)$ & 25 & 42 & 42 & 57 & 17 \\
\hline$H-9(L-3 \times L-4)$ & 6 & 5 & 13 & 9 & 7 \\
\hline$H-10(L-3 \times L-5)$ & -6 & 4 & 1 & 10 & 10 \\
\hline $\mathrm{H}-11$ (L-3 x L-6) & 6 & 8 & 3 & 7 & -3 \\
\hline $\mathrm{H}-12(\mathrm{~L}-4 \times \mathrm{L}-5)$ & 7 & 6 & 12 & 9 & 6 \\
\hline $\mathrm{H}-13(\mathrm{~L}-4 \times \mathrm{L}-6)$ & 5 & 5 & 9 & 5 & 3 \\
\hline $\mathrm{H}-14(\mathrm{~L}-5 \times \mathrm{L}-6)$ & 11 & 12 & 6 & 8 & -4 \\
\hline$\underline{\mathrm{H}-15}(\mathrm{~L}-2 \times \mathrm{L}-5)$ & 37 & 43 & 45 & 51 & 12 \\
\hline Média das heteroses & 15,7 & 20,1 & 23,3 & 26,9 & 9,7 \\
\hline
\end{tabular}

bos os parentais) e excelente complementação gênica entre as linhagens parentais para os loci com efeitos não aditivos.

As estimativas de heterose variaram de -6 a $57 \%$, sendo que os híbridos H-5, H-8 e H-15 se destacaram com os maiores valores para número e massa de frutos por planta (Tabela 4). Em média, as ensaios conduzidos no verão e de $5,1 \%$ na primavera.

Godoy et al. (2005), estudando a mesma população original [('Safira' $\mathrm{x}$ Hatem) x 'Safira' $\mathrm{F}_{2} \mathrm{RC}_{1}$ ], com zero a cinco gerações de autofecundação, observaram acentuada depressão por endogamia para produção de frutos imaturos, o que já mostrava a importância da ação gênica não aditiva, o que ficou comprovado neste trabalho.

Das 75 estimativas de heterose para características de produção, apenas três foram negativas (Tabela 4), sendo que os híbridos foram superiores a média dos pais e geralmente superiores ao parental mais produtivo. Consequentemente, não seria interessante a utilização de uma linhagem de pepino, desta população estudada, diretamente como cultivar comercial, ao contrário do relatado por alguns autores para pepino (Robinson, 1999; Rubino \& Wehner, 1986).

Pode-se concluir que tanto os efeitos aditivos como os não aditivos foram significativos para as características de produção de frutos (número e massa por planta), resultando em elevadas capacidades geral e específica de combinação e heteroses positivas para a maioria das combinações entre as linhagens.

\section{AGRADECIMENTOS}

À FAPESP, pela concessão de auxílio à pesquisa (Processo 02/12837-8).

\section{REFERÊNCIAS}

BRIM CA. 1966. A modified pedigree method of selection in soybeans. Crop Science 6: 220.

CAÑIZARES KAL. 1998. A cultura de pepino. In: GOTO R; TIVELLI SW (eds). Produção de hortaliças em ambiente protegido: condições subtropicais. São Paulo: Fundação Editora UNESP. p.195-223.

CARDOSO AII. 2002. Avaliação de cultivares de pepino tipo 'Caipira' sob ambiente protegido em duas épocas de semeadura. Bragantia 61: 43-48.

CARDOSO AII; SILVA N. 2003. Avaliação de híbridos de pepino tipo japonês sob ambiente protegido em duas épocas de cultivo. Horticultura Brasileira 21: 170-175.

CRAMER CS; WEHNER TC. 1999. Little heterosis for yield components in hybrids of six cucumber inbreds. Euphytica 110: 99-108.

CRUZ CD. 2001. Programa Genes: versão Windows. Viçosa: UFV. 648p.

CUI HW; QI YT; LIU JH; REN ZB. 1992. Correlation between parents and $\mathrm{F}_{1}$ progeny in earliness heterosis and the estimation of traits limits of parents. Cucurbit Genetics Cooperative Report 15: 13-16. 
DELANEY DE; LOWER RL. 1987. Generation means analysis of plant characters in crosses between two determinate cucumber lines and Cucumis sativus var. hardwickii. Journal of the American Society for Horticultural Science 112: 707-711.

DEMATTÊ MESP. 1978. Comportamento de cultivares de pepino (Cucumis sativus L.) em duas épocas de semeadura. 109p. Piracicaba: USP/ ESALQ. (Dissertação).

FEHR WR. 1987. Principles of cultivar development-theory and technique. New York: Mcmillan Publishing Co. 536p.

FILGUEIRA FAR. 2000. Novo manual de olericultura: agrotecnologia moderna na produção e comercialização de hortaliças. Viçosa: Editora UFV, 402p.

FILGUEIRA FAR; GIORDANO LB; FERREIRA PE; DELLA VECCHIA PT. 1986. Avaliação de híbridos $\mathrm{F}_{1}$ de pepino do tipo 'Caipira'. Horticultura Brasileira 4: 17-20.

GHADERI A; LOWER RL. 1978. Heterosis and phenotypic stability of F1 hybrids in controlled environment. Journal of the American Society for Horticultural Science 103: 275-278.
GODOY AR; OVIEDO VRS; CARDOSO AII 2005. Análise endogâmica de uma população de pepino 'Caipira'. Horticultura Brasileira 23: 785-788.

GRIFFING B. 1956. Concept of general and specific combining ability in relation to diallel crossing systems. Australian Journal of Biological Sciences 9: 463-493.

LI JW; LI JW; WEI ZD. 1995. Genetic analysis for major agronomic characters in cucumber (Cucumis sativus L.). Acta Horticulturae, The Hague 402: 388-391.

LOWER RL; EDWARDS MD. 1986. Cucumber breeding. In: BASSET MJ (eds). Breeding vegetable crops. Westport: Avi Publishing. p.173-207.

MALUF WR. 2001. Heterose e emprego de híbridos $\mathrm{F}_{1}$ em hortaliças. In: NASS LL; VALOIS ACC; MELO IS; VALADARES MC (eds). Recursos genéticos e melhoramento: plantas. Rondonópolis: Fundação MT. p. 327-356.
NOMURA ES; CARDOSO AII. 2000. Redução da área foliar e o rendimento do pepino japonês. Scientia Agricola 57: 257-261.

ROBINSON RW. 1999. Rationale and methods for producing hybrid cucurbit seed. Journal of New Seeds 1: 1-47.

ROBINSON RW; DECKER-WALTERS DS. 1999. Cucurbits. Cambridge: CAB International. 226p.

RUBINO DB; WEHNER TC. 1986. Effect of inbreeding on horticultural performance of lines developed from an open-pollinated cucumber population. Euphytica 35: 459-464.

SPRAGUE GF; TATUM LA. 1942. General versus specific combining ability in single crosses of corn. Journal of the American Society of Agronomy 34: 923-932.

VENCOVSKY R; BARRIGA P. 1992. Genética biométrica no fitomelhoramento. Revista Brasileira de Genética 496p.

VIGGIANO J. 1994. Hortaliças: cultivares e sementes. Horticultura Brasileira 12: p.252-254. 